\title{
Nutritional status of 11-12-year-old Jamaican children: coexistence of under- and overnutrition in early adolescence
}

\author{
Maria Jackson ${ }^{1, *}$, Maureen Samms-Vaughan ${ }^{1}$ and Deanna Ashley ${ }^{2}$ \\ ${ }^{1}$ Department of Child Health, University of the West Indies, Mona, Kingston 7, Jamaica, West Indies: ${ }^{2}$ Ministry of \\ Health, 2-4 King Street, Jamaica, West Indies
}

Submitted 6 November 2000: Accepted 22 August 2001

\begin{abstract}
Objective: To determine the nutritional status of a cohort of 11-12 year olds and ascertain social and demographic factors associated with under- and overweight in early adolescence.

Design: Cross-sectional.

Subjects: Subgroup $(n=1698)$ of the birth cohort (September-October 1986) of the Jamaican Perinatal Survey enrolled in schools in the Kingston Metropolitan area. One thousand and sixty-three parents or caregivers provided social and demographic information.

Results: Undernutrition and overnutrition are of public health significance among adolescent Jamaican children. Ten per cent of 11-12 year olds had body mass index (BMI) values below the 5 th percentile (boys, 10.6\%; girls, 7.1\%) but this prevalence is relatively low compared with other developing countries. The prevalence of stunting was low (3\%). The prevalence of overweight (BMI $\geq 85$ th percentile) (19.3\%) was approaching prevalence rates found in the USA. Similar social and demographic variables were associated with thinness and fatness in males. Birth weight predicted overweight in girls.

Conclusions: Under- and overnutrition in early adolescence are important problems in Jamaica. There is a need to address both under- and overnutrition in adolescence in preventive and rehabilitative intervention programmes.
\end{abstract}

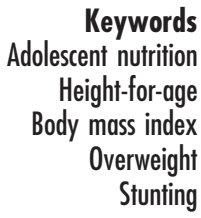

Adolescence is the transition period between childhood and adulthood and comprises persons aged 10-19 years ${ }^{1}$. Adolescents account for a disproportionately large percentage of the population in some developing countries $^{2}$ and this proportion is expected to increase in relation to other age groups ${ }^{3}$. The demography has generated much interest in health and its social implications in these countries. However, few published studies have addressed nutrition in adolescence, although this is a period of vulnerability ${ }^{4-6}$.

In the recent past, as a developing country with substantial numbers of undernourished children, Jamaica placed great emphasis on the identification of children with low anthropometric values in need of rehabilitative care. Little attention was paid to overnutrition. Social, economic and demographic transformations have occurred in the Caribbean region and the phenomenon of epidemiological transition has been accompanied by changing dietary patterns resulting in changes in the composition of the $\operatorname{diet}^{7}$. This nutrition transition is often accompanied by a reduction in activity levels, resulting in changes that predispose to overweight and obesity in later life ${ }^{8}$. As a consequence, non-communicable chronic diseases have emerged and account for an increasing share of morbidity and mortality ${ }^{\text {. }}$.

While there are studies on the influence of disparities in social status in adolescence ${ }^{10,11}$, few have investigated the relationships between sociodemographic factors and health and nutrition ${ }^{12,13}$. Adolescence is a critical stage for the development of obesity. The onset of obesity in this period of development appears to increase the risk of obesity in adulthood ${ }^{14}$. Overweight in adolescents is associated with elevated risk in adulthood for a number of non-communicable diseases including increased mortality and morbidity from heart disease, atherosclerosis, gout, hip fracture and colorectal cancer ${ }^{15}$. In view of the nutritional transition in the Caribbean countries, investigation of the nutritional status of adolescents is important for the development of nutrition intervention programmes aimed at prevention and rehabilitation.

This report is based on data from a cohort of 11-12 year olds who participated in a study of cognition, school achievement and behaviour in Jamaican children. The study focused on health, nutrition, and social and demographic factors associated with learning and 
behaviour. The paper presents cross-sectional data on the nutritional status of the cohort and provides information on social and demographic factors associated with underweight (body mass index (BMI) $<5$ th percentile) and overweight (BMI $\geq 85$ th percentile) in early adolescence.

\section{Subjects and methods}

\section{Sample and study design}

The sample consisted of a subgroup of the birth cohort of the Jamaican Perinatal Mortality and Morbidity Survey. The original cohort comprised all births, island-wide ( $n=10527)$, in the 2 -month period from September to October $1986^{16}$. Subjects for this investigation formed a geographical subgroup of the national birth cohort and included all cohort children aged 11-12 years attending schools in the Kingston Metropolitan area. The estimated population of children born September to October 1986 in these parishes was $2047^{17}$. Children were identified through the education system. Three main types of school were available for this age group: public primary, private primary and secondary schools. One hundred and six public primary, 51 private primary and 22 secondary schools are located in Kingston and St. Andrew.

Various approaches were employed for identification of the sample.

1. The 1997 and 1998 Common Entrance Examination (taken for admission to secondary school) records at the Ministry of Education were reviewed and data on eligible children in Kingston and St. Andrew extracted.

2. Principals of schools were mailed letters requesting them to identify and submit to the department a list of all eligible children (with birth dates SeptemberOctober 1986) enrolled in their institutions. Subsequent to the identification of children, letters informing parents of the study and consent forms were sent to parents through schools.

3. The Special Education Department of the Ministry of Education and the Director, Children's Services Division, Ministry of Health, were asked to forward information on children in their care.

\section{Participation rates}

A total of 1698 adolescents of the cohort enrolled in schools were included in the study, yielding a participation rate of $82.7 \%$. For $63.0 \%$ of the study children $(n=$ 1063) a biological parent or caregiver provided information on social and demographic factors. Data were collected from November 1997 to February 1999.

\section{Data collection}

\section{Anthropometry}

Weight and height were measured using standard techniques $^{18}$. Height-for-age and weight-for-age were calculated using the National Center for Health Statistics (NCHS) references. Overweight/obesity was defined as a body mass index (BMI) (weight/height ${ }^{2}$ ) at the 85 th percentile or above according to age and $\operatorname{sex}^{19}$. Intermeasurer reliability ( $n=80 ; r=0.93$ ) was high among eight anthropometrists.

\section{Measures of socio-economic status}

Socio-economic status was ascertained by the following.

1. Parents or caregivers were asked to report the highest level of education mothers and fathers had attained. Education was categorised as follows: primary schooling or less $=1$; secondary schooling $=2$; vocational training $=3$; and tertiary education $=4$.

2. Information on occupation was obtained for (1) the head of the household, (2) mother or female parenting figure and (3) father or male parenting figure. Occupation was classified according to the following scheme: unskilled and pensioners $=1$; semi-skilled $=2$; skilled manual $=3$; clerical and sales $=4$, technicians and semi-professionals $=5$; and professionals $=6$.

3. The number of household possessions (sum of television, refrigerator, living room suite, telephone, stereo equipment, cable/satellite connection, motor vehicle, washing machine and freezer; each item scored as 1).

4. The number of children $<18$ years old in the household.

5. Crowding - defined as the number of persons per sleeping room.

\section{Birth measurements}

The child's birth weight, birth order and mother's current parity were investigated as information obtained from the original survey showed that these factors influence developmental outcomes ${ }^{20,21}$.

\section{Pre-testing of questionnaires}

The questionnaire was pre-tested with adults not eligible to participate in the study in the adjoining parish of St. Catherine. Subsequently, the questionnaire was revised and the final version created for the study. Reproducibility of the questionnaire ( $n=40 ; r=0.87$ ) and inter-observer agreement $(n=40 ; r=0.94)$ were high among eight interviewers.

\section{Data analysis}

Distributions were examined for deviations from normality. Non-parametric statistics (Mann-Whitney $U$-test for skewed distributions; Chi-square statistics) were used for variables that were not normally distributed. The $t$-test and analysis of variance were used for variables that were normally distributed.

The relation of social and demographic variables to attained height and body mass index was initially screened 
by Pearson's product-moment correlation coefficients to determine associations among these factors. Variables that were associated with BMI or height/age were included in the subsequent regression models. Multivariate regression analysis (stepwise) was used to ascertain the extent to which social and demographic factors contributed to height/age $Z$-score and BMI with statistical control for age, gender and height (in BMI model) as potentially confounding factors.

Logistic regression was employed to estimate the odds ratio (OR) of being overweight (BMI $\geq 85$ th percentile) or underweight $(\mathrm{BMI}<5$ th percentile). These were calculated with statistical control for age and height as potentially confounding factors. Confidence intervals (CIs) of the odds ratios are presented.

Statistical analyses were performed by the Statistical Package for Social Sciences $^{22}$. Statistical significance was achieved when $P<0.05$.

\section{Results}

\section{Nutritional status}

Mean age and anthropometric data are displayed in Table 1. Girls were significantly taller and heavier than their male counterparts, being $3 \mathrm{~cm}$ taller and $3 \mathrm{~kg}$ heavier on average. These gender differences in height and weight probably reflect the earlier pubertal growth spurt in girls. The mean BMI and height of the girls (but not boys) were greater than those of the US reference population ${ }^{19}$.

Figure 1 shows the distribution of body mass index (weight $/$ height $^{2}$ ) among boys and girls in early adolescence. Nine per cent of adolescents were underweight (BMI $<5$ th percentile), $4 \%$ more than expected for the reference population. More boys (10.6\%) than girls (7.1\%) were thin. Fewer boys (8.4\%) than girls (11.7\%) were overweight and similar proportions (9\%) of both genders were obese ( $>95$ th percentile), thereby suggesting slight excess of overweight (among girls) and more obesity (4\% higher than expected from the NCHS reference). Evaluation of relative weight using the International Obesity Task Force (IOTF) cut-offs ${ }^{23}$ revealed 14\% of adolescents were overweight (BMI equivalent to 25.0-

Table 1 Mean weight, height and body mass index (BMI) of a subgroup of the Jamaican birth cohort aged 11-12 years

\begin{tabular}{|c|c|c|}
\hline & Males $(n=820)$ & $\begin{array}{l}\text { Females } \\
(n=878)\end{array}$ \\
\hline & Mean \pm SD & Mean \pm SD \\
\hline Age (years) & $11.7 \pm 0.3$ & $11.7 \pm 0.3$ \\
\hline Height $(\mathrm{cm})$ & $147.9 \pm 7.13$ & $151.5 \pm 7.42^{\star \star \star}$ \\
\hline Weight (kg) & $39.9 \pm 10.5$ & $43.8 \pm 11.3^{\star \star \star}$ \\
\hline $\mathrm{BMI}\left(\mathrm{kqm}^{-2}\right)$ & $18.11 \pm 3.63$ & $18.92 \pm 4.04^{\star \star *}$ \\
\hline
\end{tabular}

***, $P<0.0001$. Males significantly different from females. $S D$ - standard deviation.
$29.9 \mathrm{~kg} \mathrm{~m}^{-2}$ ) (males, $12.2 \%$; females, 15.4\%) and 6\% obese (males, 5.2\%; females, 6.6\%).

Few adolescents were stunted (height-for-age $<5$ th percentile) (Fig. 2). More girls (15.7\%) than boys (10.1\%) were tall (height-for-age $>90$ th percentile).

\section{Social background}

The characteristics of the children's homes are summarised in Table 2. A piped source of water was available to almost 95\% of households and just over three-quarters of the sample reported that water was piped inside the house. The majority of homes (90\%) had water closets and almost all used gas or electricity as the cooking fuel. Televisions (96\%) and refrigerators (87\%) were the most commonly reported household items while other possessions such as motor vehicles, washing machines and freezers were less frequently reported.

Forty-two per cent of households were headed by women. Some $23.5 \%$ of heads of households reported that they were engaged in occupations that were categorised as unskilled employment, $24.7 \%$ were in semi-skilled and $22.9 \%$ were in skilled occupations. Eighteen per cent of household heads were engaged in either technical or professional employment.

Fifty-nine per cent of children had biological parents as both parenting figures and $8 \%$ had two surrogates as parents. The mean age of children's mothers (or surrogate mother figures) was $38.5 \pm 8.3$ years and of the father figures was $41.5 \pm 8.7$ years. Thirty-five per cent of mothers and $37 \%$ of fathers had attained primary education or less and approximately $18 \%$ of both parents

Table 2 Household characteristics and housing amenities

\begin{tabular}{lc}
\hline Variable & \\
\hline Crowding (persons per sleeping room) & $2.3 \pm 1.2$ \\
Mean \pm SD & 38.0 \\
$\leq 1.99(\%)$ & 35.0 \\
$2.00-2.99(\%)$ & 27.0 \\
3.00 or more $(\%)$ & $2.7 \pm 1.5$ \\
Number of persons <18 years old in household & \\
Mean \pm SD & $5.3 \pm 2.2$ \\
Household possessions* & \\
Mean \pm SD & $75.0(877)$ \\
Source of water & $19.1(224)$ \\
Piped inside house, \% $(n)$ & $4.0(47)$ \\
Piped outside house, \% $(n)$ & $1.9(22)$ \\
Standpipe, \% $(n)$ & \\
Other sources, \% $(n)$ & $95.6(1119)$ \\
Cooking fuel & $0.8(9)$ \\
$\quad$ Gas/electric, \% $(n)$ & $3.6(42)$ \\
Kerosene, $\%(n)$ & \\
Wood/coal, \% $(n)$ & $70.1(818)$ \\
Toilet facilities & $20.1(235)$ \\
Water closet - unshared, \% $(n)$ & $6.3(74)$ \\
Water closet - shared, \% $(n)$ & $3.4(40)$ \\
Pit toilet - unshared, \% $(n)$ & \\
Pit toilet - shared, \% $(n)$ &
\end{tabular}

*Household possessions - sum of television, refrigerator, living room suite, telephone, stereo equipment, cable/satellite connection, motor vehicle, washing machine and freezer; each item scored as 1.

SD - standard deviation. 


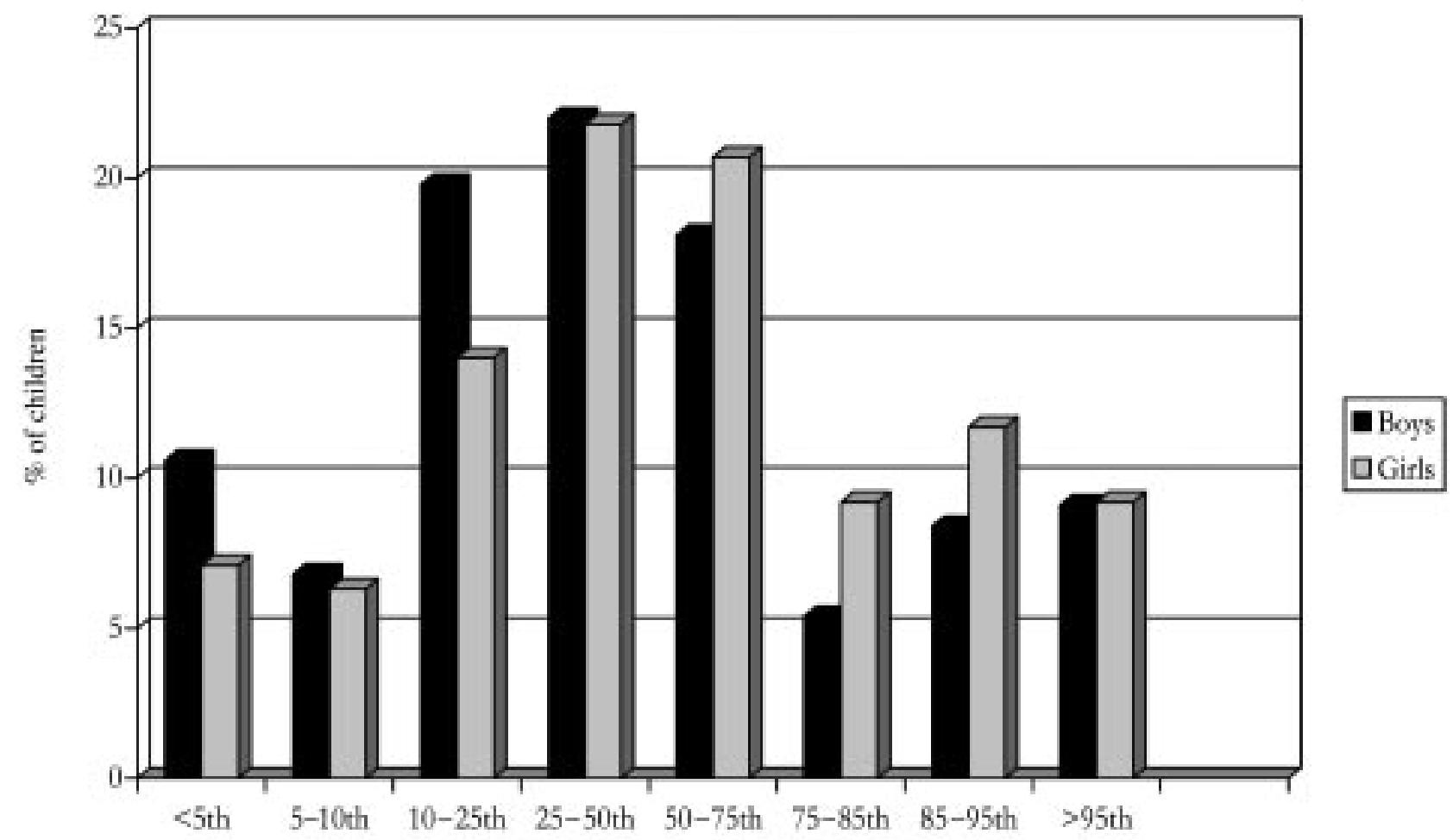

\section{BMI percentiles}

Fig. 1 Body mass index (percentiles) of the cohort of 11-12 year olds

had attended colleges or universities. Educational level was unknown for 3.5\% of mothers and it was unknown for $14 \%$ of fathers. The mean number of children was $3.2 \pm$ 1.7 and the average birth order of the study children was $1.3 \pm 1.6$.

\section{Associations of social and demographic factors with nutritional status}

Univariate analyses revealed modest correlations between nutrition variables and social and demographic characteristics of adolescents (data not shown). Taller adolescents were from homes with a higher social status. Height-for- age was significantly and positively correlated with occupation of the head of household $(r=0.14$; $P<0.001)$ and higher possessions score $(r=0.15$; $P<0.001$ ), and negatively correlated with crowding and the number of children $<18$ years old living in the household. Mother's parity was negatively related to height and birth weight was positively associated with height-for-age.

Regarding body mass index, with the exception of education of parents which was not correlated, all variables that were correlated with height-for-age were also associated with BMI; the directions remained but the

Table 3 Stepwise regressions of social and demographic variables* on heightfor-age $Z$-score and body mass index (BMI)

\begin{tabular}{|c|c|c|c|}
\hline & $\mathrm{B} \pm \mathrm{SE}$ & Sig. $t$ & $r^{2}$ \\
\hline \multicolumn{4}{|l|}{ Height-for-age Z-score } \\
\hline Age (years) & $-0.539 \pm 0.147$ & 0.0001 & 0.034 \\
\hline Birth weight (kg) & $0.438 \pm 0.087$ & 0.0001 & 0.044 \\
\hline Number of $<18$ year olds in household & $-0.109 \pm 0.033$ & 0.001 & 0.020 \\
\hline \multicolumn{4}{|l|}{ BMI $\left(\mathrm{kg} \mathrm{m}^{-2}\right)$} \\
\hline Gender & $1.020 \pm 0.321$ & 0.002 & 0.012 \\
\hline Number of $<18$ year olds in household & $-0.581 \pm 0.113$ & 0.0001 & 0.041 \\
\hline Birth weight $(\mathrm{kg})$ & $1.348 \pm 0.309$ & 0.0001 & 0.025 \\
\hline & & & \\
\hline
\end{tabular}




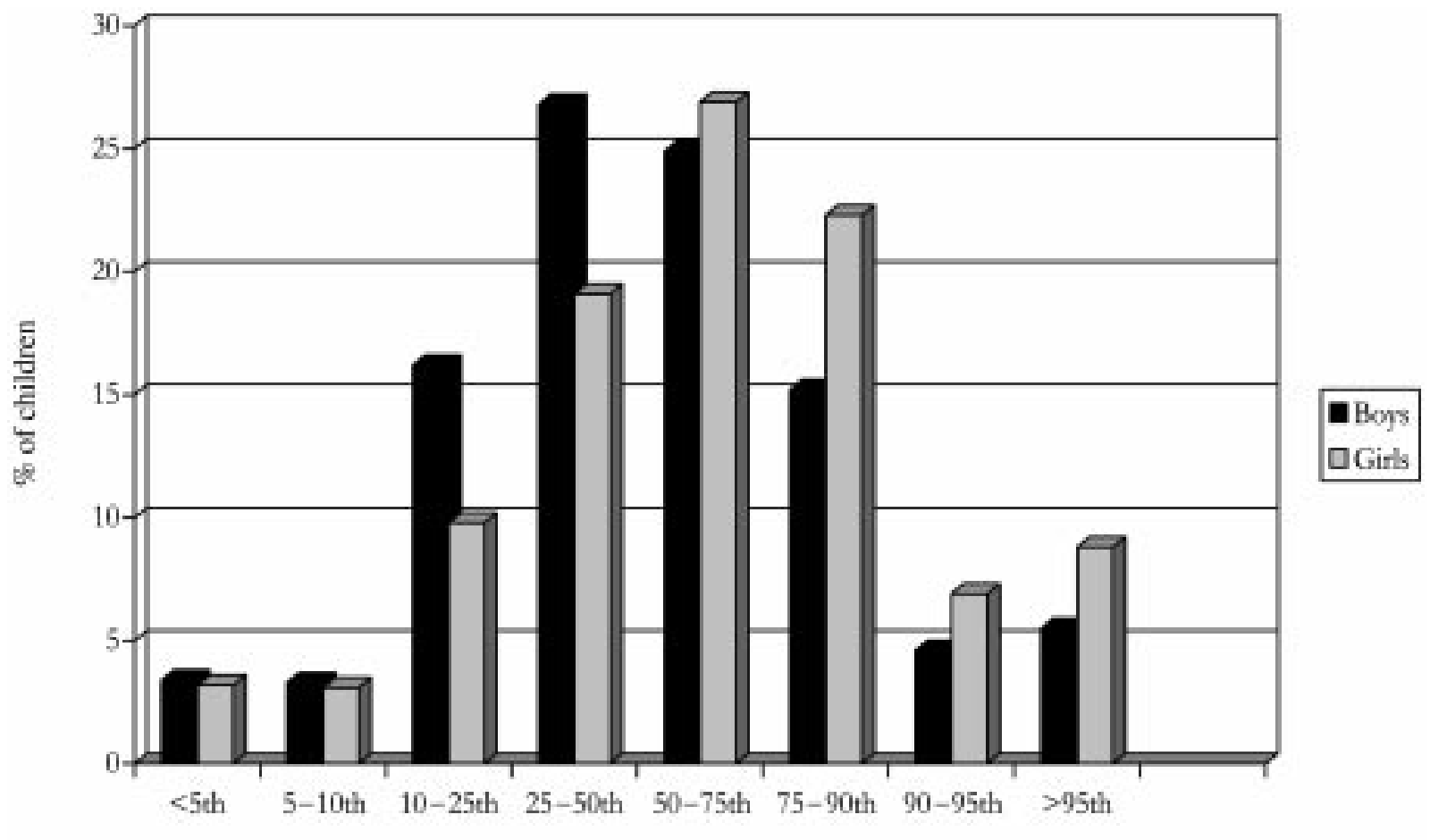

Height-for-age percentiles

Fig. 2 Height-for-age (percentiles) of the cohort of 11-12 year olds

degree of associations varied. In addition, the child's height and the age of mother and father figures were positively associated with BMI.

Variables that were significantly correlated in univariate analyses were offered stepwise in multiple linear regressions of height-for-age and BMI to ascertain the extent to which social and demographic factors contributed to nutritional status. Age and gender were entered in both regressions (Table 3). The child's height was included in the BMI model.

Younger age and higher birth weights were associated with higher height-for-age $Z$-scores. Height-for-age was negatively associated with larger numbers of children of $<18$ years in the household. Nine per cent of the variance was explained in this model.

Children of higher birth weights and girls had higher BMIs. Adolescents of lower socio-economic status, as reflected in the number of $<18$ year olds in the household, had lower BMIs.

Logistic regression analyses were used to identify significant correlates of overweight (BMI $\geq 85$ th percentile) and underweight (BMI $<5$ th percentile) among males and females. Odds ratios were calculated to estimate the strength of the relation of social and demographic factors to under- and overnutrition, adjusting for the child's age and height.

In males, two variables predicted undernutrition (BMI $<5$ th percentile) (Table 4). Boys in crowded households were more likely to be underweight (OR 4.3; CI
1.4-9.7). On the contrary, compared with boys whose mothers had 2 or fewer children, adolescent boys whose mothers were of higher parity (3 or more) were less likely to be thin (OR 0.3; CI 0.1-0.9). Neither social nor demographic variables predicted undernutrition in girls.

The data in Table 4 show that young adolescent boys in crowded households (OR 0.4; CI 0.2-0.8) and of high

Table 4 Odds ratios for the likelihood of $\mathrm{BMI}<5$ th percentile and $\mathrm{BMI} \geq 85$ th percentile by social and demographic factors

\begin{tabular}{llllll}
\hline & \multicolumn{2}{c}{ Males } & & \multicolumn{2}{c}{ Females } \\
\cline { 2 - 3 } \cline { 5 - 6 } Variable & $n$ & OR $(95 \% \mathrm{Cl})$ & & $n$ & OR $(95 \% \mathrm{Cl})$ \\
\hline
\end{tabular}

\section{$B M K$ 5th percentile}

Crowding (persons per sleeping room)

$\begin{array}{llcl}<1.99 & 18 & 1.0 & 24 \\ 2.00 \text { or more } & 26 & 4.3(1.4-9.7) & 23 \\ \text { Parity } & & & \\ 1-2 & 18 & 1.0 & 16 \\ 3.0 \text { or more } & 29 & 0.3(0.1-0.9) & 34\end{array}$

\section{$B M I \geq 85$ th percentile}

Crowding (persons per sleeping room)

$\begin{array}{llc}<1.99 & 74 & 1.0 \\ 2.00 \text { or more } & 26 & 0.4(0.2-0.8)\end{array}$

Parity

$\begin{array}{lll}1-2 & 57 & 1.0\end{array}$

3.0 or more $\quad 45 \quad 0.4(0.2-0.9)$

Birth weight

$\begin{array}{lrrr}>2.5 \mathrm{~kg} & 87 & 113 & 1.0\end{array}$

$<2.5 \mathrm{~kg}$

5

$7 \quad 0.3(0.1-0.9)$

Odds ratios are adjusted for all the other variables: age, height, occupation of the head of the household, number of individuals $<18$ years old and household possessions. 
parity (OR 0.4; CI 0.2-0.9) were at decreased risk of being overweight. Among girls, neither social nor demographic factors were significant, however birth weight was inversely related to risk of overweight and suggested that, compared with girls whose weight at birth was at or greater than $2.5 \mathrm{~kg}$, low birth weight $(<2.5 \mathrm{~kg})$ adolescent girls were less likely to be overweight.

\section{Discussion}

Cross-sectional results of the nutritional status of a subgroup of young adolescents from a 2-month birth cohort and the social demographic factors associated with body mass are reported. The findings revealed that both under- and overnutrition are of public health significance. The coexistence of these nutritional conditions reflects the nutritional transition occurring in Jamaica. Almost twice as many children were underweight compared with the NCHS reference population and obesity showed a $4 \%$ excess. Only two of the social and demographic variables considered (crowding and parity) were associated with BMI and predicted both under- and overweight in males but not in females. Among females, low birth weight was associated with reduced risk of overweight.

The subgroup comprised children attending schools in the Kingston Metropolitan area and the findings may not be generalisable to rural children. BMI was the only measure of adiposity. In adolescence the BMI is not independent of height and reflects both fat and lean body mass $^{24}$. Despite the limitations, the BMI $\left(\mathrm{kg} \mathrm{m}^{-2}\right)$ has been proposed as the preferred method for screening overweight and obesity in adolescence ${ }^{25}$ as it is significantly correlated with body fatness in adolescents ${ }^{26,27}$ and is highly specific as a measure of body fat ${ }^{28}$.

Nutritional status of 11-12 year olds as measured by weight and height compared favourably to the US reference population ${ }^{19}$. Girls were taller, heavier and had higher BMI than boys. Not surprisingly, therefore, a greater proportion of boys than girls were undernourished (BMI $<5$ th percentile). More girls (11.7\%) than boys $(8.4 \%)$ were overweight and equal proportions were obese (9\%). The same number of boys (17.4\%) were identified as overweight by the IOTF cut-offs and the 85 th percentile of the NCHS references. Similar numbers of girls (IOTF, 22\%; NCHS, 20.7\%) were identified.

\section{Linear growth}

Linear growth is influenced by environmental and genetic factors. Low height-for-age (stunting) occurs in early childhood and is a result of substandard diet and infections $^{29}$. Heights of 11-12 year olds compared well with the US reference values ${ }^{19}$. Mean attained heights of boys and girls fell between the 50th and 75 th percentiles of the US age and sex distribution. Very few adolescents (3.4\% boys; $3.2 \%$ girls) had height-for-age $<5$ th percentile, indicating a relatively low prevalence of stunting in early adolescence.

There were modest correlations between social, demographic and biological variables and height. However, when these variables were offered in multivariate analyses, only the child's age, birth weight and the number of $<18$ year olds in the household were associated with height. Poor children are often from large households and, as would be expected, larger households were associated with lower attained height. Data from developed and developing countries report that socio-economic status contributes substantially to variance in height ${ }^{13,30}$. However, only $2 \%$ of the variance in height-for-age of young adolescents was explained by socio-economic variables.

\section{BMI (under- and overnutrition)}

Mean BMI of adolescent boys and girls was within the normal weight category (50th-75th percentiles) of the NCHS references ${ }^{19}$. However, $8.7 \%$ of adolescents had a BMI value below the 5 th percentile and undernutrition was higher among boys. This level of undernutrition was much lower than the prevalence rates in other developing countries such as 10-18 year olds in India (53\%), Nepal (36\%) and Benin (23\%) $)^{5}$ and adolescents $10-13$ years in China $(18 \%)^{4}$. Our finding of gender differences in undernutrition in this study is similar to that observed in other studies in less developed countries ${ }^{4,5}$. Although the prevalence of undernutrition was moderate, it is of concern since undernutrition in adolescence may affect mental, behavioural and emotional maturation ${ }^{31-33}$.

In the present study $19.3 \%$ of adolescents had $\mathrm{BMI} \geq 85$ th percentile, approaching the prevalence rates of over $20 \%$ found in the USA ${ }^{8,34}$. There are few reports on the prevalence of overweight from other developing countries but our results are strikingly different from the prevalence among adolescents in China $(4 \%)^{4}$. The magnitude of gender differences in $\mathrm{BMI} \geq 85$ th percentile was significant, and agrees with other studies that report a higher prevalence of overweight in girls ${ }^{35}$. Dietz ${ }^{14}$ suggests that adolescence is a critical period for the development of obesity and gender differences in the 'entrainment' of obesity confer higher risks for females in adulthood. It is of significance to note that in a recent survey of adult Jamaicans, approximately 30\% of women and $7 \%$ of men were obese $\left(\mathrm{BMI}>30 \mathrm{~kg} \mathrm{~m}^{-2}\right)^{36}$. The only indicator of social status that influenced BMI was the number of $<18$ year olds in the household. As with heightfor-age, the percentage variance in BMI explained was small. Characteristics such as health-related behaviours and psychological variables that were not measured in this study may partially explain the differential in overweight.

Higher birth weight was predictive of higher height and BMI. The observation that birth weight predicted weight and height is generally consistent with the results of other studies in growth in later childhood ${ }^{37,38}$. Our findings suggest that birth weight not only influences 
growth in the formative years, but also is extended to early adolescence.

Our study revealed that similar factors were determinants of under- and overnutrition among males only. Overcrowding and parity (3 or more) influenced both thinness and fatness. On the one hand, crowding increased the risk of $\mathrm{BMI}<5$ th percentile and was also protective of young adolescent boys being overweight (BMI $\geq 85$ th percentile). These findings are plausible as a large number of dependants in a household limits the quality and quantity of household resources, including food, available for each child, and is generally accepted to be an index of poverty. Similar associations between socio-economic variables and anthropometry were seen in older adolescent girls (13-14 years) in Kingston ${ }^{6}$.

In our study, higher parity of the child's mother was associated with reduced risk of overnutrition and undernutrition among boys. The inverse relation between parity and undernutrition was somewhat surprising as high parity is likely to be related to lower social status and might be expected to be associated with increased risk of undernutrition.

This study showed that low birth weight predicted decreased risk of having $\mathrm{BMI} \geq 85$ th percentile. The intrauterine environment, as reflected in birth weight, has been shown to exert effects extending to relative weight in adults ${ }^{37}$. However, the evidence supporting the relationship is inconclusive, with some studies reporting that low birth weight is associated with greater fatness ${ }^{38,39}$ while others have not ${ }^{40-42}$. Our data must be viewed with caution, as the number of low birth weight subjects was small.

In conclusion, almost 20\% of young adolescents were overweight (BMI $\geq 85$ th percentile) but undernutrition remained an important nutritional problem. These findings illustrate the nutrition transition that Jamaica is undergoing, with the coexistence of undernutrition and overnutrition. Thinness was more common among boys whereas girls were more likely to be fat. The same variables predicted over- and undernutrition among boys. Lower social status was related to reduced risk of overweight, similar to the case in other societies undergoing the epidemiological transition ${ }^{43}$, and has not yet reached the situation of industrialised countries in which individuals of lower social status are at higher risk of being overweight. The findings highlight the dilemma faced by countries in transition, where preventative and rehabilitative intervention programmes need to address both under- and overnutrition in adolescence.

\section{Acknowledgements}

This study was supported by the Policy Development Unit, Planning Institute of Jamaica. The authors gratefully acknowledge Professor Susan Walker for her careful review of drafts of this manuscript.

\section{References}

1 World Health Organization (WHO). Young People's Health: A Challenge for Society. Technical Report Series No. 731. Geneva: WHO, 1986.

2 United Nations. Demographic Year Book, 1995, 47th ed. New York: United Nations, 1997.

3 Blum RW. Global trends in adolescent health. J. Am. Med. Assoc. 1991; 265(20): 2711-9.

4 Wang Y, Popkin B, Zhai F. The nutritional status and dietary patterns of Chinese adolescents, 1991 and 1993. Eur. J. Clin. Nutr. 1998; 52: 908-16.

5 Kurz KM. Adolescent nutritional status in developing countries. Proc. Nutr. Soc. 1996; 55: 321-31.

6 Walker SP, Grantham-McGregor SM, Himes JM, Williams S. Anthropometry in adolescent girls in Kingston, Jamaica. Ann. Hum. Biol. 1996; 23: 23-9.

7 Popkin BM. The nutrition transition in low-income countries: an emerging crisis. Nutr. Rev. 1994; 52: 285-98.

8 Popkin BM, Udry JR. Adolescent obesity increases significantly in second and third generation US immigrants: the National Longitudinal Study of Adolescent Health. J. Nutr. 1998; 128: 701-6.

9 Pena M, Freire WB. Report of a Seminar-Workshop on Obesity and Poverty in Latin America, Havana, Cuba, 15-19 May 1995. Pan American Health Organization Document, PAHO/HPP/HPN 96.02. Cuba: WHO Regional Office, 1996.

10 Billewicz WZ, Thomson AM, Fellowes HM. A longitudinal study of growth in Newcastle upon Tyne adolescents. Ann. Hum. Biol. 1983; 10: 125-33.

11 Goodman E. The role of socioeconomic status gradients in explaining differences in US adolescents' health. Am. J. Public Health 1999; 89(10): 1522-8.

12 Rona RJ, Swan AV, Altman DG. Social factors and height of primary school children in England and Scotland. J. Epidemiol. Comm. Health 1978; 32: 147-54.

13 Jones YD, Nesheim MC, Habicht JP. Influences in child growth associated with poverty in the 1970's: an examination of HANES1 and NHANESII, cross-sectional US national surveys. Am. J. Clin. Nutr. 1985; 42: 714-24.

14 Dietz WH. Critical periods in childhood for the development of obesity. Am. J. Clin. Nutr. 1994; 59: 955-9.

15 Must A, Jacques PF, Dallal GE, Bajema CJ, Dietz WH. Longterm morbidity and mortality of overweight adolescent: a follow-up of the Harvard Growth Study of 1922 to 1935. N. Engl J. Med. 1992; 1327: 1350-5.

16 Ashley D, McCaw-Binns A, Golding J, Keeling J, Escoffery C, Coard K, Foster-Williams K. Perinatal mortality survey in Jamaica: aims and methodology. Pediatr. Perinatal Epidemiol 1994; 8(Suppl. 1): 6-16.

17 Statistical Institute of Jamaica. Population Census Reports [unpublished]. Statistical Institute of Jamaica, Kingston, Jamaica, 1997

18 Lohman TG, Roche AF, Martorell R. Anthropometric Standardization Reference Manual. Champaign, IL: Human Kinetics Books, 1988.

19 National Center for Health Statistics (NCHS). CDC Growth Charts: United States [Online]. Available at http://www.cdc. gov/growthcharts. 10 May 2001.

20 Samms-Vaughan M, Jackson M, Ashley D. Cognition, Educational Attainment and Behaviour in a Cohort of Jamaican Children. Report. Mona, Jamaica: University of the West Indies, 1998.

21 Samms-Vaughan M, Jackson M, Ashley D. The Relationship of Prenatal Factors to Later Childhood Development and Behaviour in a Cohort of 11-12 year old Jamaican Children. Report. Mona, Jamaica: University of the West Indies, 2000.

22 SPSS, Inc. Statistical Package for Social Scientists, version 7.5.2. Chicago, IL: SPSS Inc., 1997. 
23 Cole TJ, Bellizzi MC, Flegal KM, Dietz WH. Establishing a standard definition for child overweight and obesity worldwide: international survey. BMJ 2000; 320: 1240-3.

24 Garn SM, Leonard WR, Hawthorne VM. Three limitations of the body mass index. Am. J. Clin. Nutr. 1986; 44: 996-7.

25 Himes JH, Dietz WH. Guidelines for overweight in adolescent preventive services: recommendations from an expert committee. The Expert Committee on Clinical Guidelines for Overweight in Adolescent Preventive Services. Am. J. Clin. Nutr. 1994; 59: 307-16.

26 Roche AF, Siervogel FM, Chumlea WC, Webb P. Grading body fatness from limited anthropometric data. Am. J. Clin. Nutr. 1981; 34: 2831-8.

27 Durenberg P, Westrate JA, Seidell JC. Body mass index as a measure of body fatness: age- and sex- specific prediction formulas. Br. J. Nutr. 1991; 65: 105-14.

28 Marshall JD, Hazlett CB, Spady DW, Quinney HA. Comparison of convenient indicators of obesity. Am. J. Clin. Nutr. 1990; 51: 22-8.

29 Martorell R, Habicht JP. Growth in early childhood in developing countries. In: Falkner F, Tanner JM, eds. Human Growth: A Comprehensive Treatise. Vol. 3. Methodology: Ecological, Genetic and Nutritional Effects on Growth, 2nd ed. New York/London: Plenum Press, 1986.

30 Habicht J-P, Martorell R, Yarbrough C, Malina RM, Klein RE. Height and weight standards for preschool children. How relevant are ethnic differences in growth potential. Lancet 1974; 1: 611-5.

31 Pollitt E. Poverty and child development: relevance of research in developing countries to the United States. Child Dev. 1994; 65: 283-95.

32 Agarwal KN, Agarwal DK, Upadhydal SK. Impact of chronic undernutrition on higher mental function in boys aged 1-12 years. Acta Paediatr. 1995; 84: 1357-61.

33 Grantham-McGregor S. A review of the studies of the effects of severe malnutrition on mental development. J. Nutr. 1995; 125(Suppl. 8): 2233S-8S.

34 Troiana RP, Flegal KM, Kuczmarski RJ, Campbell SM, Johnson CL. Overweight prevalence and trends for children and adolescents. Arch. Ped. Adolesc. Med. 1995; 149: 1085-91.

35 Garn SM, La Velle M, Rosenberg KR, Hawthorn VM. Maturational timing as a factor in female fatness and obesity. Am. J. Clin. Nutr. 1986; 43: 879-83.

36 Wilks R, Bennett F, Forrester T, McFarlane-Anderson N. Chronic diseases: the new epidemic. West Ind. Med. J 1998; 47(Suppl 4): 40-4.

37 Whitaker RC, Dietz WH. Role of the prenatal environment in the development of obesity. J. Pediatr. 1998; 132: 768-76.

38 Curhan GC, Chertow GM, Willett WC, Spiegleman D, Colditz GA, Manson JE, Speizer FE, Stampfer MJ. Birthweight and adult hypertension and obesity in women. Circulation 1996; 94: $1310-5$.

39 Fall CHD, Osmond C, Barker DJP, Clark PMS, Hales CN, Stirling Y, Meade TW. Fetal and infant growth and cardiovascular risk factors in women. BMJ 1995; 310: 428-32.

40 Ravelli ACJ, van der Meulen JHP, Osmond C, Barker DJP, Bleker OP. Obesity at the age of $50 \mathrm{yr}$ in men and women exposed to famine prenatally. Am. J. Clin. Nutr. 1999; 70: 811-6.

41 Paz I, Seidman DS, Danon YL, Laor A, Stevenson DK, Gale R. Are children born small FDR gestational age at increased risk of short stature? Am. J. Dis. Child. 1993; 147: 337-9.

42 Martorell R, Ramakrishnan U, Schroeder DG, Melgar P, Neufield L. Intrauterine growth retardation, body size, body composition and physical performance in adolescence. Eur. J. Clin. Nutr. 1998; 51: S43-53.

43 Pena M, Bacallao J, eds. Obesity and Poverty: A New Public Health Challenge. PAHO Scientific Publication 576. Washington, DC: Pan American Health Organization, 2000. 